\title{
Turunç (Citrus aurantium L.) odununun bazı mekanik özelliklerinin belirlenmesi ve bazı odun türleri karşılaştırılması
}

\author{
Vedat Çavuş*(i)
}

$\ddot{\mathbf{O z}}$

Turunç ağacı (Citrus aurantium L.) Rutaceae familyasına aittir. Çeşitli dillerde ve ülkelerde farklı isimlerle anılır, örneğin; naranja ácida, naranja agria veya naranja amarga (İspanya), naranji; (Arabistan), melangolo (İtalya), khatta (Hindistan), moli (Samoa), sabun portakalı (Guam). Sert, beyaz veya açık sarı renkteki odunu marangozluk, tornalama, dolap yapımı ve beyzbol sopası yapımında kullanılır. Her ağaç türüne ait belirlenmiş olan mekanik ve fiziksel özellikleri ahşabın kullanımı hakkında önemli bilgilerin ortaya çıkmasına yardımcı olmaktadır. Bu çalışmada, İzmir'de yetişen turunç (Citrus aurantium L.) ağacına ait odun örnekleri üzerinde hava kurusu yoğunluk değeri, eğilme direnci, eğilmede elastikiyet modülü, şok direnci, vida tutma dirençleri (teğet, radyal ve enine) belirlenmiştir. Elde edilen sonuçlara göre; hava kurusu yoğunluk değeri $\left(D_{12}\right) 868 \mathrm{~kg} / \mathrm{m}^{3}$, eğilme direnci $134.7 \mathrm{~N} / \mathrm{mm}^{2}$, eğilmede elastikiyet modülü $8988 \mathrm{~N} / \mathrm{mm}^{2}$, şok direnci $0.683 \mathrm{kgm} / \mathrm{cm}^{2}$, vida tutma dirençleri teğet yüzeyde $55.8 \mathrm{~N} / \mathrm{mm}^{2}$, radyal yüzeyde $57.7 \mathrm{~N} / \mathrm{mm}^{2}$ ve enine yüzeyde $52.6 \mathrm{~N} / \mathrm{mm}^{2}$ olarak belirlenmiştir. Elde edilen bu sonuçların birçok ağaç türüne kıyasla yüksek sonuçlar olduğu görülmüştür.

Anahtar kelimeler: Turunç odunu, eğilme direnci, şok direnci, vida tutma direnci

\section{Determination of some mechanical properties of bitter orange wood (Citrus aurantium $\mathbf{L}$.) and comparison with some other woods}

\begin{abstract}
Bitter orange wood (Citrus aurantium L.) belongs to the Rutaceae family. It is called by different names in various languages and country for example; naranja ácida, naranja agria, or naranja amarga (Spain), naranji; (Arabia), melangolo (Italy), khatta (India), moli (Samoa), soap orange (Guam). The hard, white or light-yellow wood is used in woodworking, turning, cabinet making, and baseball bats. The mechanical and physical properties of each tree species help to create important information about the use of wood. In this study, air-dry density value, bending resistance, modulus of elasticity in bending, impact bending strength, screw holding resistance (tangent, radial and transverse) were determined on wood samples of bitter orange tree grown in İzmir. According to the results obtained; air-dry density value $\left(D_{12}\right) 868 \mathrm{~kg} / \mathrm{m}^{3}$, bending resistance $134.7 \mathrm{~N} / \mathrm{mm}^{2}$, elasticity modulus $8988 \mathrm{~N} / \mathrm{mm}^{2}$ in bending, impact bending strength $0.683 \mathrm{kgm} / \mathrm{cm}^{2}$, screw holding resistance $55.8 \mathrm{~N} / \mathrm{mm}^{2}$ at tangent surface, $57.7 \mathrm{~N} / \mathrm{mm}^{2}$ at radial surface and $52.6 \mathrm{~N} / \mathrm{mm}^{2}$ at the transverse surface. It has been observed that these results are higher compared to many tree species.
\end{abstract}

Keywords: Bitter orange, modulus od rupture, modulus of elasticity, screw holding strength

Makale tarihçesi: Geliș: 18.11.2020, Kabul: 02.12.2020, Yayınlanma: 28.12.2020, *e-posta: vedatcavus@ hotmail.com *İzmir Kâtip Celebi Üniversitesi, Orman Fakültesi, Orman Endüstri Mühendisliği Bölümü, İzmir/Türkiye

Atıf: Çavuş V. (2020), Turunç odununun bazı mekanik özelliklerinin belirlenmesi ve diğer bazı ağaç odunları ile karşılaştırılması, Mobilya ve Ahşap Malzeme Araştırmaları Dergisi, 3(2),101-109. DOI: 10.33725/mamad.828000 


\section{Giriş}

Citrus aurantium L. ssp. amara Engl. acı portakal, Sevilla portakalı, ekşi portakal olarak bilinir (eşanlamlısı C. aurantium L. subsp. aurantium) ve Rutaceae familyasına aittir. Kuzey Hindistan (Hindistan, Assam' daki Khasia Tepeleri ve Orta İller), Güneydoğu Asya ile Akdeniz, Amerika'nın 1lıman bölgelerinde doğal olarak yetişir. Bu ağaç 6 ila 8 metre yükssekliğinde, kalın dış kabuğu olan meyvelere sahiptir (Quintero ve diğ., 2003).

Turunç odununda hava kurusu yoğunluk değeri $760.08 \mathrm{~kg} / \mathrm{m}^{3}$, janka sertlik değerleri teğet, radyal ve enine yüzeyler için sırasıyla $80.09 \mathrm{~N} / \mathrm{mm}^{2}, 76.48 \mathrm{~N} / \mathrm{mm}^{2}$ ve $82.25 \mathrm{~N} / \mathrm{mm}^{2}$, çivi tutma dirençleri teğet, radyal ve enine yüzeyler için sırasıyla $13.62 \mathrm{~N} / \mathrm{mm}^{2}, 20.24 \mathrm{~N} / \mathrm{mm}^{2}$ ve 17.94 $\mathrm{N} / \mathrm{mm}^{2}$ ve $1 \mathrm{~s} 1$ iletkenlik değeri $0.149 \mathrm{~W} / \mathrm{mK}$ olarak belirlenmiştir (Ayata ve diğ., 2019).

Turunç ağacına ait kereste sert ve ince lifli olmaktadır. Tornacılık (değerli eşyalar, vb.) ve dolap yapımında değerlidir. Ayrıca Küba'da turunç odunundan beyzbol sopasının yapıldığı da bildirilmiştir (Morton 1987). Citrus'a ait soyulmuş kabuklardan çıkarılan ekstraktları sabun yapımında, mobilya cilaları yapımında, el temizleyicileri olarak ve evcil hayvanlar için şampuan yapımında kullanılmaktadır (Manner ve diğ., 2006).

Genellikle yiyecekler için bir tatlandırıcı ve asitleştirici madde olarak kullanılmaktadır (Karabıyıklı ve diğg., 2014). Uçucu yağ ve bileşenlerinin (Moraes ve diğg., 2009, Barceloux 2008) yanı sıra, meyveleri, çeşitli biyolojik etkilere sahip olup flavonoid tipi bileşiklerin kaynaklarıdır (Liu ve diğ., 2008, Kang ve diğ., 2011, Hamada ve diğ., 2017). Buna ek olarak, flavonoid glikozitlerin bitkiden (Zhang ve diğ., 2017) izole edildiği ve biyojenik amin ve flavanon içeriklerinin belirlendiği de literatürde bildirilmiştir (Pellati ve diğ., 2004, Bagatela ve diğ., 2015). Hindistan'daki en önemli 3. meyve mahsulüdür. Etno-tıbbi uygulamas1 uzun süredir bilinmektedir (Periyanayagam ve diğ., 2013). Geleneksel olarak mide ağrısı, kusma, kan basıncı, öksürük, soğuk algınlığı, bronşit, kulak ağrısı, dizanteri, ishal, karın ağrısı ve ateş gibi geniş bir yelpazedeki hastalıkların tedavisi için yararlı olduğu bilinmektedir. İdrar yolu enfeksiyonları rahatsızlıkları için kabuğu kullanılmıştır. Kurutulmuş çiçeğin infüzyonu, grip, uykusuzluk, kardiyovasküler analeptik, anti spazmodik, soğuk, yatıştırıcı, sindirim için ağızdan kullanılır. Kök, çıban ve idrar yolu enfeksiyonlarının tedavisinde kullanılmaktadır (Karthikeyan ve Karthikeyan, 2014).

$\mathrm{Bu}$ çalışmada, İzmir'de yetişen turunç (Citrus aurantium L.) ağaç türüne ait odun örneklerinde hava kurusu yoğunluk değeri, eğilme direnci, eğilmede elastikiyet modülü, şok direnci, vida tutma dirençleri (teğet, radyal ve enine) belirlenmiştir. Yapılan literatür araştırmasında bu ağaç türüne ait odununda bu testlerin yapılmadığı görülmüsşür. Ancak benzer bir meyve ağacı olan portakal odunun parke endüstrisinde kullanılmasının araştırılmıştır. Bu araştırmaya göre portakal ağaçlarından elde edilen odunun ince taneli olduğu, yüksek yoğunluğa $\left(827 \mathrm{~kg} / \mathrm{m}^{3}\right)$ sahip olduğu, boyutsal stabilitesinin ortalama değerlerde olduğu ve yüksek yüzey sertliği $\left(4,8 \mathrm{~kg} / \mathrm{mm}^{2}\right)$ değerlerine sahip olduğu tespit edilmiştir. Ayrıca bu odun türünün dikkatli bir şekilde kurutulması önerilmiştir (Berti ve diğ., 2018). Bu çalışmada elde edilen sonuçların bu ağaç türüne ait literatür dünyasına önemli katkılarda bulunacağı düşünülmektedir.

\section{Materyal ve Metot}

\subsection{Materyal}

Bu çalışmada, İzmir'de yetişen Turunç (Citrus aurantium L.) ağaç türüne ait odun örnekleri ticari bir kereste şirketinden satın alınma yoluyla temin edilmişstir. 


\subsection{Metot}

\subsubsection{Fiziksel özelliklerin belirlenmesi}

Test örneklerinin hava kurusu yoğunluk değeri ( $\left.\mathrm{D}_{12}\right)$ TS 2472'de belirtilen esaslara göre ve vida tutma direnci test örnekleri üzerinde hesaplanmıştır.

\subsubsection{Mekanik özelliklerin belirlenmesi}

Test örneklerinin eğilme direnci TS 2474'e, eğilmede elastikiyet modülü TS 2478 'e, şok direnci TS 2477'ye ve vida tutma direnci ise TS EN 13446'da belirtilen esaslara uygun olarak yapılmıştır. Bu testlere ait görüntüler sırasıyla Şekil 1-A, B ve C'de verilmiştir. Eğilme direnci

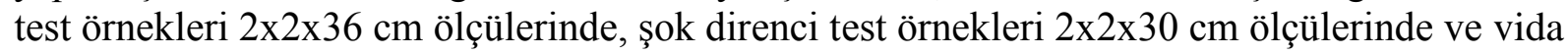
tutma direnci test örnekleri $5 \times 5 \times 5 \mathrm{~cm}$ ölçülerinde hazırlanmıştır (Şekil 1-D). Vida tutma direncinde ön delik çapı $2.5 \mathrm{~mm}$, vida çapı $4 \mathrm{~mm}$, vida boyu $50 \mathrm{~mm}$ ve vida girme derinliği 20 $\mathrm{mm}$ olarak alınmıştır. Eğilme direncinde mesnetler arası mesafe 30 ve şok direncinde $24 \mathrm{~cm}$ olarak ayarlanmıştır. Eğilme direnci ve şok direnci testinde kuvvet radyal yüzeye uygulanmıştır.
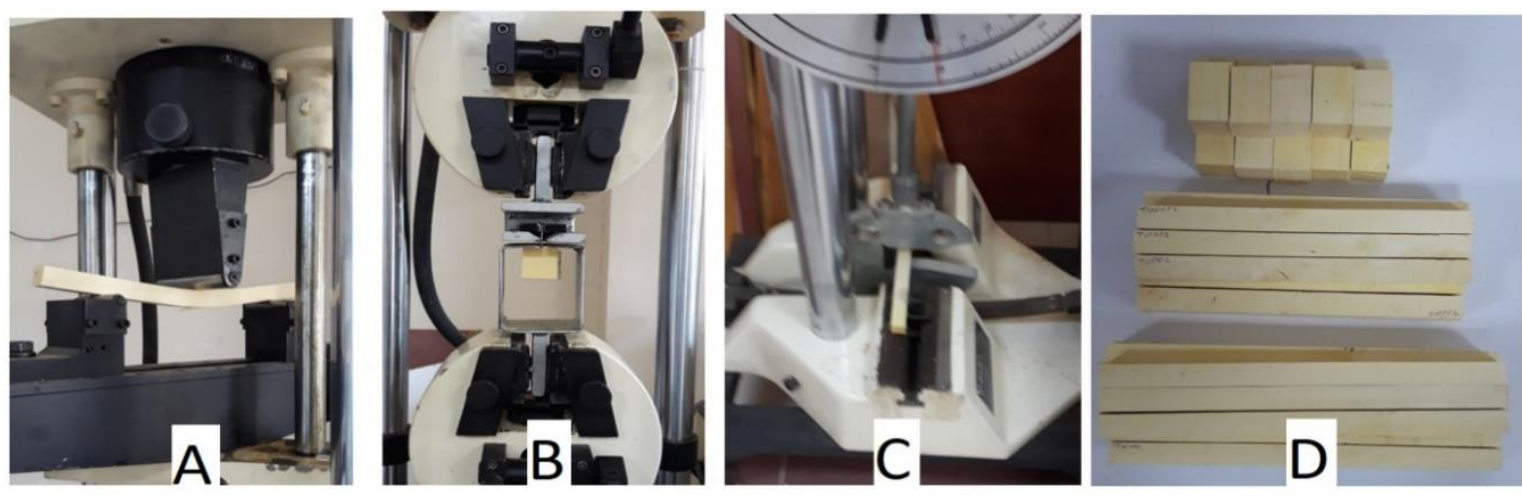

Şekil 1. Mekanik özelliklerin test görüntüsü (A: eğilme direnci, B: vida tutma, C: şok direnci) ve test örneklerinin görüntüsü (D)

\section{Bulgular ve Tartışma}

Turunç odununda belirlenmiş olan hava kurusu yoğunluk, eğilme direnci, eğilmede elastikiyet modülü, şok direnci ve vida tutma dirençlerine ait sonuçları Çizelge 1'de, vida tutma kapasiteleri kıyaslamaları Çizelge 2'de, eğilme direnci kıyaslamaları Çizelge 3'de, eğilmede elastikiyet modülü kıyaslanmaları Çizelge 4'de ve şok direnci değerlerinin kıyaslamaları Çizelge 5'de verilmiştir. Elde edilen sonuçlara göre; hava kurusu yoğunluk değeri $\left(\mathrm{D}_{12}\right) 868$ $\mathrm{kg} / \mathrm{m}^{3}$, eğilme direnci $134.7 \mathrm{~N} / \mathrm{mm}^{2}$, eğilmede elastikiyet modülü $8988 \mathrm{~N} / \mathrm{mm}^{2}$, şok direnci $0.683 \mathrm{kgm} / \mathrm{cm}^{2}$, vida tutma dirençleri teğet yüzey için $55.8 \mathrm{~N} / \mathrm{mm}^{2}$, radyal yüzey için 57.7 $\mathrm{N} / \mathrm{mm}^{2}$ ve enine yüzey için $52.6 \mathrm{~N} / \mathrm{mm}^{2}$ olarak elde edilmiştir (Çizelge 1 ).

Sertlik, ağaç malzemenin deformasyona direnme yeteneğini ifade edee ve en önemli özellikleri arasındadır. Aynı zamanda yoğunluk ve mekanik özellikler ile de yakından ilişkilidir. Ağaç malzemede sertlik bu malzemenin işlenebilirliği hakkında önemli bir parametredir (Doyle ve Walker, 1985). Literatürde, sertliğin ağaçtan ağaca büyük farklar gösterdiği ifade edilmiştir (Şanıvar ve Zorlu 1980). Ayrıca, eğilme direnci testine ait kuvvet - deformasyon grafiği Şekil 2'de ve test örneklerinin test sonrası görüntüsü Şekil 3'de gösterilmektedir. Çizelge 2'de bazı ağaç türlerinde belirlenmiş olan vida tutma kapasitelerine göre en düşük sonuç enine yüzeylerde elde edildiği görülmektedir. Buna ek olarak, turunca ait tutma kapasitesi, lhlamur, kestane, tespih, ceviz, maun, akçaağaç manolya, kayısı ve limon ağaç türlerinden yüksek olduğu 
görülmektedir. Ahşap ve ahşap esaslı malzemelerdeki vidaların tutma kuvveti üzerine birçok çalışma yapılmıştır. Sonuçlar, ahşap esaslı malzemenin türüne, fiziksel ve mekanik özelliklerine, boyutuna, numune şekline, pilot deliğin çapına, konektör tipine, numunedeki montaj yönüne ve ayrıca çekme oranına bağlı olduğunu bildirmiştir (Fairchild 1926, Rajak ve Eckelman 1993, Eckelman 1988, Erdil ve Zhang 2002, Gates 2009).

Çizelge 1. Turunç odununda belirlenmiş olan hava kurusu yoğunluk, eğilme direnci, eğilmede elastikiyet modülü, şok direnci ve vida tutma dirençlerine ait sonuçları

\begin{tabular}{|l|c|c|c|c|}
\hline \multicolumn{1}{|c|}{ Test } & Ortalama & $\begin{array}{c}\text { Standart } \\
\text { Sapma }\end{array}$ & Minimum & Maksimum \\
\hline Hava kurusu yoğunluk değeri $\left(\mathrm{D}_{12}\right)\left(\mathrm{kg} / \mathrm{m}^{3}\right)$ & 868.00 & 15.00 & 850.00 & 895.00 \\
\hline Ĕgilme direnci $\left(\mathrm{N} / \mathrm{mm}^{2}\right)$ & 134.70 & 16.50 & 92.80 & 154.80 \\
\hline Eğilmede elastikiyet modülü $\left(\mathrm{N} / \mathrm{mm}^{2}\right)$ & 8988.00 & 687 & 7843.00 & 10108.00 \\
\hline Şok direnci $\left(\mathrm{kgm} / \mathrm{cm}^{2}\right)$ & 0.683 & 0.285 & 0.391 & 1.247 \\
\hline Vida tutma direnci teğet yüzeyde $\left(\mathrm{N} / \mathrm{mm}^{2}\right)$ & 55.80 & 3.70 & 47.80 & 61.90 \\
\hline Vida tutma direnci radyal yüzeyde $\left(\mathrm{N} / \mathrm{mm}^{2}\right)$ & 57.70 & 4.00 & 49.90 & 66.10 \\
\hline Vida tutma direnci enine yüzeyde $\left(\mathrm{N} / \mathrm{mm}^{2}\right)$ & 52.60 & 2.80 & 49.10 & 58.70 \\
\hline
\end{tabular}

Çizelge 2. Bazı ağaç türlerinde belirlenmiş olan vida tutma kapasitelerinin kıyaslamaları $\left(\mathrm{N} / \mathrm{mm}^{2}\right)$

\begin{tabular}{|c|c|c|c|c|}
\hline Ağaç Türü & Teğet & Radyal & Enine & Kaynak \\
\hline Ihlamur (Tilia grandifolia Ehrh.) & 19.53 & - & - & Bal ve diğ., (2018c) \\
\hline Kestane (Castanea sativa Mill.) & 22.95 & - & - & Bal ve diğ., (2018c) \\
\hline Tespih (Melia azedarach L.) & 35.66 & 30.31 & 24.02 & Çavuş ve Ayata (2018) \\
\hline Ceviz (Juglans regia L.) & 36.41 & - & - & Bal ve diğ., (2018c) \\
\hline Maun (Swietenia mahagoni) & 38.36 & - & - & Bal ve diğ., (2018c) \\
\hline Akçaağaç (Acer trautvetteri Medw.) & 39.91 & 36.63 & 33.45 & Çavuş ve Ayata (2018) \\
\hline Manolya (Magnolia grandiflora) & 38.40 & 32.53 & 30.40 & Çavuş ve Ayata (2018) \\
\hline Kayıs (Prunus armeniaca L.) & 48.89 & 47.34 & 44.38 & Çavuş (2020b) \\
\hline Limon (Citrus limon (L.) Burm) & 50.80 & 53.98 & 43.62 & Şahin ve diğ., (2020) \\
\hline Turunç (Citrus aurantium L.) & $\mathbf{5 5 . 8 0}$ & $\mathbf{5 7 . 7 0}$ & $\mathbf{5 2 . 6 0}$ & Tespit \\
\hline Çitlembik (Celtis australis L.) & $\mathbf{5 8 . 1 0}$ & 59.60 & 55.80 & Çavuş (2020c) \\
\hline
\end{tabular}

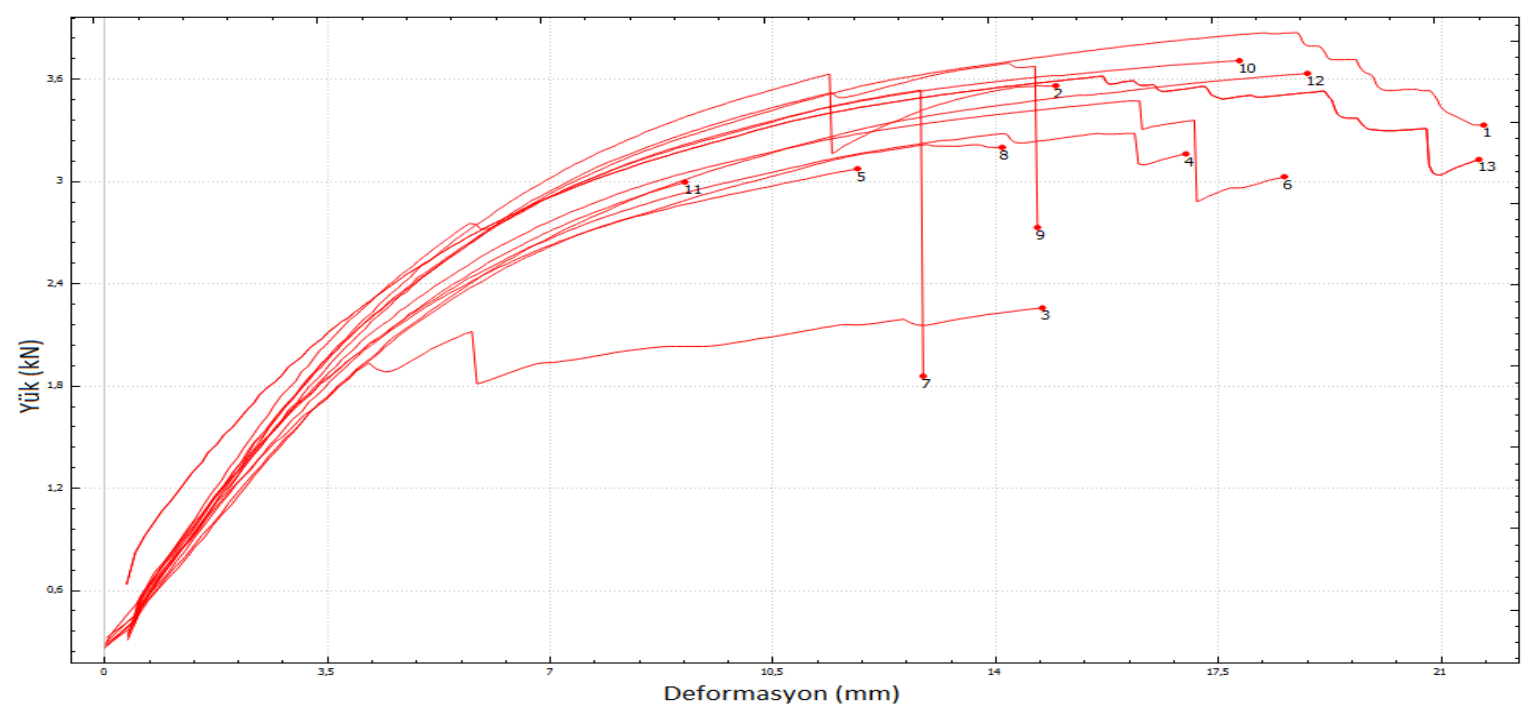

Şekil 2. Eğilme direnci testine ait kuvvet - deformasyon grafiği 


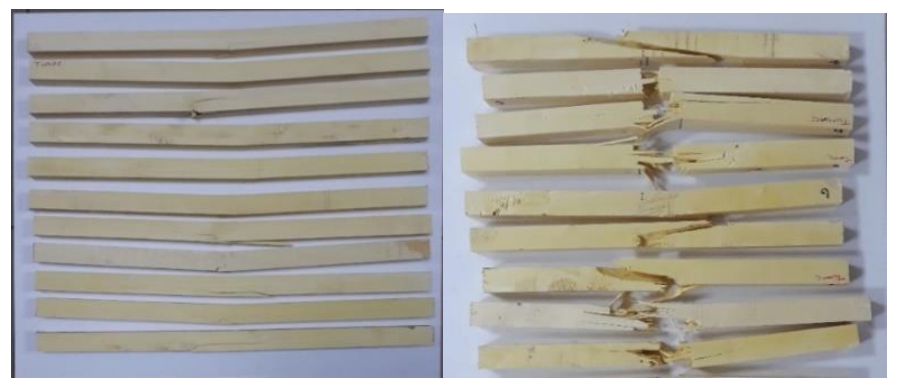

Şekil 3. Test örneklerinin test sonrası görüntüsü (A: eğilme direnci, B: şok direnci)

Ahşabın darbeye karşı direnci, çarpma eğilme mukavemetini içerir. Zaman bileşeni önemlidir, çünkü darbe yükü anlıktır. Daha yüksek darbe direncine sahip bir malzeme daha sertken, daha düşük bir darbe eğilme mukavemetine sahip ahşap daha kırılgandır (Kollmann 1984). Bir malzemenin esneklik modülü, sertliğinin bir ölçüsü olup, kirişlerin sapmasının hesaplanmasında yapısal kerestenin elastikiyet modülü kullanılmaktadır (Ambrose 1997). Çizelge 3, 4 ve 5'e göre turunç odununun şok direnci, eğilme direnci ve elastikiyet modülü sonucu birçok ağaç türünden yüksek elde edilmiştir.

Çizelge 3. Bazı ağaç türlerinde belirlenmiş olan eğilme dirençlerinin kıyaslamaları

\begin{tabular}{|c|c|c|}
\hline Ăgaç Türü & $\mathrm{N} / \mathbf{m m}^{2}$ & Kaynak \\
\hline Gülibrişim (Albizia julibrissin) & 63.70 & Çavuş (2019a) \\
\hline Kavak (Populus spp) & 71.20 & Şahin ve diğ., (2006) \\
\hline Toros sediri (Cedrus Libani A. Richard) genç odun & 75.80 & Bal ve diğ., (2012) \\
\hline Kayıs1 (Prunus armeniaca L.) & 81.88 & Çavuş (2020b) \\
\hline Manolya (Magnolia grandiflora L.) & 85.56 & Çavuș (2019b) \\
\hline Kokar ardıç (Juniperus foetidissima Willd.) & 93.80 & Çavuş (2020a) \\
\hline Toros sediri (Cedrus Libani A. Richard) olgun odun & 94.40 & Bal ve diğ., (2012) \\
\hline Kayın (Fagus orientalis L.) diri odun & 95.70 & Bal ve Bektaş (2018) \\
\hline Kayın (Fagus orientalis L.) öz odun & 98.30 & Bal ve Bektaş (2018) \\
\hline Çitlembik (Celtis australis L.) & 108.10 & Çavuş (2020c) \\
\hline Kara servi (Cupressus sempervirens) & 113.27 & Bal ve diğ., (2018b) \\
\hline Turunç (Citrus aurantium L.) & 134.70 & Tespit \\
\hline Huş (Betula pendula) & 135.92 & Bal ve diğ., (2018a) \\
\hline
\end{tabular}

Çizelge 4. Bazı ağaç türlerinde belirlenmiş olan eğilmede elastikiyet modülü kıyaslanmaları

\begin{tabular}{|c|c|c|}
\hline Ăgaç Türü & $\mathbf{N} / \mathbf{m m}^{\mathbf{2}}$ & Kaynak \\
\hline Kavak (Populus x euramericana I-214) öz odun & 4357.00 & Bal ve Bektaş (2018) \\
\hline Gülibrişim (Albizia julibrissin) & 5029.00 & Çavuş (2019a) \\
\hline Kavak (Populus x euramericana I-214) diri odun & 5882.00 & Bal ve Bektaş (2018) \\
\hline Toros sediri (Cedrus Libani A. Richard) genç odun & 6668.20 & Bal ve diğ,, (2012) \\
\hline Manolya (Magnolia grandiflora L.) & 6375.66 & Çavuş (2019b) \\
\hline Kayısı (Prunus armeniaca L.) & 6569.00 & Çavuş (2020b) \\
\hline Kokar ardıç (Juniperus foetidissima Willd.) & 6701.50 & Çavuş (2020a) \\
\hline Çitlembik (Celtis australis L.) & 8247.10 & Çavuş (2020c) \\
\hline Kayın (Fagus orientalis L.) diri odun & 8306.00 & Bal ve Bektaş (2018) \\
\hline Kayın (Fagus orientalis L.) öz odun & 8710.00 & Bal ve Bektaş (2018) \\
\hline Toros sediri (Cedrus Libani A. Richard) olgun odun & 8963.30 & Bal ve diğ., (2012) \\
\hline Turunç (Citrus aurantium L.) & $\mathbf{8 9 8 8 . 0 0}$ & Tespit \\
\hline Kara servi (Cupressus sempervirens) & 13203.00 & Bal ve diğ., (2018b) \\
\hline Huş (Betula pendula) & 16887.00 & Bal ve diğ., (2018a) \\
\hline
\end{tabular}


Çizelge 5. Bazı ağaç türlerinde belirlenmiş olan şok direnci değerlerinin kıyaslamaları

\begin{tabular}{|c|c|c|}
\hline Ăgaç Türü & $\mathbf{k g m} / \mathrm{cm}^{2}$ & Kaynak \\
\hline Kokar ardıç (Juniperus foetidissima Willd.) & 0.280 & Çavuş (2020a) \\
\hline Manolya (Magnolia grandiflora L.) & 0.378 & Çavuş (2019b) \\
\hline Okaliptüs (Eucalyptus grandis) & 0.544 & Bektaş ve diğ., (2008) \\
\hline Huş (Betula pendula) & 0.680 & Bal ve diğ., (2018a) \\
\hline Turunç (Citrus aurantium L.) & 0.683 & Tespit \\
\hline Çitlembik (Celtis australis L.) & 1.530 & Çavuş (2020c) \\
\hline
\end{tabular}

\section{Sonuçlar ve Öneriler}

Bu çalışmada, İzmir' de yetişen turunç (Citrus aurantium L.) odun türünde hava kurusu yoğunluk değeri, eğilme direnci, eğilmede elastikiyet modülü, şok direnci, vida tutma dirençleri (teğet, radyal ve enine) belirlenmiş olunup, aşağıdaki sonuçlara ulaş1lmıştır:

- Fiziksel özelliklerden hava kurusu yoğunluk değeri $868 \mathrm{~kg} / \mathrm{m}^{3}$ olarak,

- Mekanik özelliklerden; şok direnci $0.683 \mathrm{kgm} / \mathrm{cm}^{2}$, eğilme direnci $134.7 \mathrm{~N} / \mathrm{mm}^{2}$, eğilmede elastikiyet modülü $8988 \mathrm{~N} / \mathrm{mm}^{2}$, vida tutma dirençleri teğet yüzeyde 55.8 $\mathrm{N} / \mathrm{mm}^{2}$, radyal yüzeyde $57.7 \mathrm{~N} / \mathrm{mm}^{2}$ ve enine yüzeyde $52.6 \mathrm{~N} / \mathrm{mm}^{2}$ olarak belirlenmiştir.

- $\mathrm{Bu}$ ağaç türüne ait ahşap yüzeylere çeşitli üst yüzey işlemlerinin uygulanması (vernik, UV sistem vernik vb.) ve uygulanacak olan üst yüzey kimyasalları için çeşitli testlerin (renk, parlaklık, yüzeye yapışma direnci, salınımsal sertlik, çizilme vb.) yapılması ile turunç odunu ile vernik arasındaki ilişkinin bilinmesi önerilmektedir.

\section{Kaynaklar}

Ambrose, J., (1997), Simplified Design of Wood Structures, Fifth Edition, Paperback, 368 pages, Published February 21st 1997 by Wiley. ISBN: 0471179892.

Ayata, Ü., Bal, B.C., ve Şahin, S., (2019). Turunç odununda 1sı iletkenlik değeri, statik sertlik ve çivi tutma direncinin belirlenmesi, Çukurova 3. Uluslararası Yenilikçi Bilimsel Araştırmalar Kongresi, 3-6 Ekim, Adana, Türkiye, 423-430.

Bagatela, B.S., Lopes, A.P., Cabral, E.C., Perazzo, F.F., and Ifa, D.R., (2015), Highperformance thin-layer chromatography / desorption electrospray ionization mass spectrometry imaging of the crude extract from the peels of Citrus aurantium L. (Rutaceae), Rapid Communications in Mass Spectrometry, 29(16), 1530-1534. DOI: 10.1002/rcm.7246.

Bal, B.C., Ayata, Ü., Çavuş, V., Şahin, S., Efe, F.T., ve Dilik, T., (2018a), Huş (Betula pendula) odununun bazı fiziksel ve mekanik özelliklerinin araştırılması, IV. Uluslararası Mesleki ve Teknik Bilimler Kongresi (UMTEB), 7-9 Aralık, Erzurum, Türkiye, 2104-2113.

Bal, B.C., Ayata, Ü., Çavuş, V., Şahin, S., Efe, F.T., ve Dilik, T., (2018b), İzmir'de yetişen kara servi (Cupressus sempervirens) odununun bazı fiziksel ve mekanik özelliklerinin belirlenmesi, IV. Uluslararası Mesleki ve Teknik Bilimler Kongresi (UMTEB), 7-9 Aralık, Erzurum, Türkiye, 2098-2103.

Bal, B.C., Ayata, Ü., Çavuş, V., ve Efe, F.T., (2018c), Ceviz, maun, kestane ve ihlamur odunlarında vida tutma kapasitesinin belirlenmesi, 5. Uluslararası Multidisipliner Çalışmaları Kongresi, Bildiri Tam Metin Kitabı, 02-03 Kasım, Antalya, Türkiye, 1(1): 383-396. 
Bal, B.C., Bektaş, İ., ve Kaymakçı, A., (2012), Toros sedirinde genç odun ve olgun odunun bazı fiziksel ve mekanik özellikleri, KSU Mühendislik Bilimleri Dergisi, 15(2), 17-27.

Bal, B.C., ve Bektaş, İ., (2018), Odunun yoğunluğu ile bazı mekanik özellikleri arasındaki ilişkinin belirlenmesi üzerine bir araştırma, Mobilya ve Ahşap Malzeme Araştırmaları Dergisi, 1(2), 51-61. DOI: 10.33725/mamad.467353.

Barceloux, D.G., (2008), "Citrus Oil and Limonene," in Medical Toxicology of Natural Substances, pp. 635-643, John Wiley \& Sons, Inc, Hoboken, NJ, USA.

Bektaş, İ., Alma, M.H., Bal, B.C., ve Ayata, Ü., (2008). Okaliptüs (Eucalyptus grandis W. Hill.) odununun dinamik eğilme direncinin belirlenmesi ve bazı ağaç türleri ile karşılaştırılması, I. Ulusal Okaliptüs Sempozyumu, 15-17 Nisan, Tarsus, Türkiye, 274-280.

Berti, S., Burato, P., Dionisi-Vici, P., and Allegretti, O. (2018), Orange wood for parquet and engineered flooring use, BioResources, 13(1), 586-596.

Çavuş, V., (2019a), İzmir'de yetişen gülibrişim (Albizia julibrissin) odununun bazı mekanik ve fiziksel özellikleri ile yüzey özelliklerinin belirlenmesi, Türkiye Ormancılık Dergisi, 20(4), 440-447. DOI: 10.18182/tjf.611994.

Çavuş, V., (2019b), Manolya (Magnolia grandiflora L.) odununun bazı fiziksel ve mekanik özellikleri, MAS 10th International European Conference on Mathematics, Engineering, Natural \& Medical Sciences, December 14-15, 2019, İzmir, Türkiye, 44-52.

Çavuş, V., (2020a), Ardıç odununun bazı fiziksel ve mekanik özellikleri üzerine bir araştırma, Mobilya ve Ahşap Malzeme Araştırmalarl Dergisi, 3(1), 1-9. DOI: 10.33725/mamad.717060.

Çavuş, V., (2020b), Kayısı ağacı (Prunus armeniaca L.) odununun bazı fiziksel ve mekanik özelliklerinin belirlenmesi, Bartın Orman Fakültesi Dergisi, 22(2), 457-464. DOI: 10.24011/barofd.729707.

Çavuş, V., (2020c), Çitlembik (Celtis australis L.) odununun bazı fiziksel ve mekanik özelliklerinin belirlenmesi, 1st International Hazar Scientific Research Conference, 1820 September 2020, Baku, Azerbaijan, 912-927.

Çavuş, V., ve Ayata, Ü., (2018), Manolya ağacı, akçaağaç ve tespih ağacı odunlarında vida tutma direnci üzerine bir araştırma, Mobilya ve Ahşap Malzeme Araştırmaları Dergisi, 1(2), 94-102. DOI: 10.33725/mamad.496615.

Doyle, J., Walker, J.C.F. (1985), Indentation hardness of wood, Wood Fiber Sci., 17, 369376.

Eckelman, C., (1988), The withdrawal strength of screws from commercially available medium density fiberboard, Forest Products Journal, 38(5): 21-24.

Erdil, Y.Z.. and Zhang, J., (2002), Holding strength of screws in plywood and oriented strand board, Forest Products Journal, 52(6): 55-62.

Fairchild, I.J. (1926), Holding power of wood screws. US Government Printing Office.

Gates, J.C., (2009), Screw withdrawal strength in 9 Wood's Assemblies, Oregon Wood Innovation Center, Test Evaluation Report.

Hamada, Y., Nakajima, M., Tsuzuki, K., Amakura, Y., Yoshimura, M., Okuyama, S., and Furukawa, Y., (2017), Heptamethoxyflavone reduces phosphodiesterase activity and Tcell growth in vitro, International Archives of Allergy and Immunology, 174(3-4), 113120. DOI: $10.1159 / 000481094$. 
Kang, S.R., Park, K.I., Park, H.S., Lee, D.H., Kim, J.A., Nagappan, A., Kim, E.U., Lee, W.S., Shin, S.C., Park, M.K., Han, D.Y., and Kim, G.S., (2011), Anti-inflammatory effect of flavonoids isolated from Korea Citrus aurantium L. on lipopolysaccharide-induced mouse macrophage RAW 264.7 cells by blocking of nuclear factor-kappa B (NF- $\kappa \mathrm{B})$ and mitogen-activated protein kinase (MAPK) signalling pathways, Food Chemistry, 129(4), 1721-1728. DOI: 10.1016/j.foodchem.2011.06.039.

Karabıyıklı, Ş., Değirmenci, H., and Karapınar, M., (2014), Inhibitory effect of sour orange (Citrus aurantium) juice on Salmonella Typhimurium and Listeria monocytogenes, LWT - Food Science and Technology, 55(2), 421-425. DOI: 10.1016/j.lwt.2013.10.037.

Karthikeyan, V., and Karthikeyan, J., (2014), Citrus aurantium (Bitter Orange): A review of its traditional uses, phytochemistry and pharmacology, International Journal of Drug Discovery and Herbal Research (IJDDHR), 4(4): 766-772.

Kollmann, F.F.P., and Cote, W.A., (1984), Principles of Wood Science and Technology. Volume I.: Solid Wood, Springer-Verlag, Berlin.

Liu, L., Shan, S., Zhang, K., Ning, Z.Q., Lu, X.P., and Cheng, Y.Y., (2008), Naringenin and hesperetin, two flavonoids derived from Citrus aurantium up-regulate transcription of adiponectin, Phytotherapy Research, 22(10), 1400-1403. DOI: 10.1002/ptr.2504.

Manner, H.I., Buker, R.S., Smith, V.E., Ward, D., and Elevitch, C.R., (2006), Citrus (Citrus) and Fortunella (Kumquat), Species Profile for Pacific Island Agroforestry, 2: 1-35.

Moraes, T.M., Kushima, H., Moleiro, F.C., Santos, R.C., Rocha, L.R.M., Marques, M.O., Vilegas, W., and Hiruma-Lima, C.A., (2009), Effects of limonene and essential oil from Citrus aurantium on gastric mucosa: role of prostaglandins and gastric mucus secretion, Chemico-Biological Interactions, 180(3), 499-505. DOI: 10.1016/j.cbi.2009.04.006.

Morton, J., (1987). Fruits of Warm Climates, Julia F. Morton, Miami, Florida.

Pellati, F., Benvenuti, S., and Melegari, M., (2004), High-performance liquid chromatography methods for the analysis of adrenergic amines and flavanones in Citrus aurantium L. var. amara, Phytochemical Analysis, 15(4), 220-225. DOI: 10.1002/pca.771.

Periyanayagam, K., Dhanalakshmi, S., Karthikeyan, V., and Jegadeesan, S., (2013), Phytochemical studies and GC/MS analysis on the isolated essential oil from the leaves of Citrus aurantium Linn, Journal of Natural products Plant Resources, 3(6), 19-23.

Quintero, A., de Gonzalez, C.N., Sanchez., F., Usubillaga, A., Rojas, L., and Szoke, E., (2003), Constituents and biological activity of Citrus aurantium amara L. essential oil, Acta Horticulturae, 597, 115-117.

Rajak, Z.I.B.H.A.. and Eckelman, C.A., (1993), Edge and face withdrawal strength of large screws in particleboard and medium density fiberboard, Forest Products Journal, 43(4), 25-30.

Şahin, S., Ayata, Ü., Bal, B.C., Esteves, B., Can, A., and Sivrikaya, H., (2020), Determination of some wood properties and response to weathering of Citrus limon (L.) Burm wood, Bioresources, 15(3), 6840-6850. DOI: 10.15376/biores.15.3.6840-6850.

Şahin, S., Karaman, S., ve Örüng, İ., (2006), Tokat-Niksar yöresinde yetiştirilen ve yöredeki tarımsal yapılarda yaygın olarak kullanılan kavak ağacının önemli fiziksel ve mekanik özellikleri, GÖ̈, Ziraat Fakültesi Dergisi, 23(1), 61-66. 
Şanıvar, N., ve Zorlu, İ., (1980), Ağaç işleri gereç bilgisi temel ders kitabı, Mesleki Ve Teknik Öğretim Kitapları, Milli Eğitim Basımevi, İstanbul, Etüd ve Programlama Dairesi Yayınları No: 43, 472 sayfa.

TS 2472 (1976), Odunda, fiziksel ve mekaniksel deneyler için birim hacim ağırlığı tayini, Türk Standartları Enstitüsü (TSE), Ankara.

TS 2474 (1976), Odunun statik eğilme dayanımının tayini, Türkiye Standartlar Enstitüsü (TSE), Ankara.

TS 2477 (1976), Odunun çarpmada eğilme dayanımının tayini, Türkiye Standartlar Enstitüsü (TSE), Ankara.

TS 2478 (1976), Odunun statik eğilmede elastiklik modülünün tayini, Türkiye Standartlar Enstitüsü (TSE), Ankara.

TS EN 13446, (2005), Ahşap Esaslı Levhalar - Bağlayıcıların Geri Çıkma Kapasitesinin Tayini, Türk Standartları Enstitüsü, Ankara.

Zhang, X.L., Xu, W.F., Chen, G., Wang, H.F., and Pei, Y.H., (2017), Two new phenolic glycosides isolated from the fruits of Citrus aurantium, Chinese Journal of Natural Medicines, 15(1), 41-44. DOI: 10.1016/S1875-5364(17)30006-7. 